\title{
Spectrum of associated congenital heart defects in patients with "Non-Cardiac Congenital defects at a tertiary care children hospital in Pakistan"
}

\author{
Muhammad Sohail Arshad', Muhammad Aslam², \\ Shahnab Ahmad ${ }^{3}$, Muhammad Kashif ${ }^{4}$
}

\begin{abstract}
Objectives: To assess the frequency and pattern of associated congenital heart disease (CHD) among patients with "non-cardiac congenital defects".

Methods: An observational study was done at Paediatric Cardiology Department, The Children's Hospital and The Institute of Child Health, Multan, Pakistan, from December 2018 to November 2019. Children from birth to 15 years having non-cardiac congenital defects, referred for cardiac evaluation from surgical unit during the study period were enrolled. Echocardiography was done to confirm diagnosis of CHD by consultant pediatric cardiologist.

Results: Out of a total of 323 cases, 176 (54.5\%) were male. Out of 323 patients, 160 (49.5\%) belonged to age one month to one year. Vascular malformations were the most frequent primary diagnosis among our cases, seen in $69(21.4 \%)$ children followed by cleft lip and palate $55(17.2 \%)$, cleft palate only $52(16.1 \%)$, Cleft lip only $40(12.4 \%)$ and ARM high variety $33(10.2 \%)$. CHD was found among $42(13.0 \%)$ children while patent ductus arteriosus (PDA) and VSD were the commonest finding seen in $14(33.3 \%)$ and $6(14.3 \%)$ children respectively.

Conclusion: Frequency of associated CHD among patients with non-cardiac congenital defects was high (13.0\%). Children with cleft lip and/or palate should be given more attention because of the high incidence of $\mathrm{CHD}$ in this group. Echocardiography must be advised for the timely identification of any possible type of CHD.
\end{abstract}

KEYWORDS: Congenital heart disease, Cleft lip, Echocardiography, Patent ductus arteriosus.

doi: https://doi.org/10.12669/pjms.37.3.3604

How to cite this:

Arshad MS, Aslam M, Ahmad S, Kashif M. Spectrum of associated congenital heart defects in patients with "Non-Cardiac Congenital defects at a tertiary care children hospital in Pakistan". Pak J Med Sci. 2021;37(3):695-699.

doi: https://doi.org/10.12669/pjms.37.3.3604

This is an Open Access article distributed under the terms of the Creative Commons Attribution License (http://creativecommons.org/licenses/by/3.0), which permits unrestricted use, distribution, and reproduction in any medium, provided the original work is properly cited.

\section{INTRODUCTION}

Congenital cardiac anomalies may co-exist with non-cardiac congenital malformations and,

Correspondence:

Dr. Muhammad Sohail Arshad, Associate Professor,

Head of Department of Paediatric Cardiology,

The Children's Hospital \& The Institute of Child Health, Multan, Pakistan.

E-mail: drsohailarshadchc@gmail.com

* Received for Publication:

September 4, 2020

* Revision Received:

* Revision Accepted: for those requiring surgical correction, there can be an anesthesia risk. ${ }^{1}$ This often necessitates a request for cardiovascular evaluation, including echocardiography (echo) as part of the preanesthesia evaluation to reduce anesthesia risk. ${ }^{2}$

Patients undergoing non-cardiac surgery may have conditions commonly associated with congenital heart diseases (CHD), such as children with cleft lip and palate, diaphragmatic hernia, omphalocele, tracheoesophageal fistula, skeletal anomalies, anorectal malformations and congenital vascular malformations. ${ }^{3}$ The presence of congenital anomalies in one system may be associated with increased incidence of congenital 
anomalies in other systems. ${ }^{4}$ It is imperative that children with such suspected cardiac anomalies or those with conditions commonly associated with CHD undergoing non-cardiac surgery should be evaluated for the presence of cardiovascular anomaly. ${ }^{2}$

From the studies in developing countries, the prevalence of CHD in children with cleft lip and palate ranges from $9-20 \% .5,6$ The prevalence is higher in those with cleft palate than in those with cleft lip only. This relatively high prevalence of CHD in children with oro-facial cleft has prompted the policy in most centers of pre-anaesthetic echo for all such patients. ${ }^{2}$

Congenital heart defects (CHD) are considered to be the most important form of congenital defects causing high rates of morbidity and mortality among children. ${ }^{7}$ CHD is defined as the structural or functional heart defect which is present at the time of birth even if detection is made later on. Among children undergoing surgery for non-cardiac congenital malformations, atrial septal defect (ASD) has been noted to be the most frequent cardiac anomaly observed in $25 \%$ children followed by ventricular septal defect (VSD) in $5.8 \% .^{8}$

In a resource limited country like Pakistan, delayed diagnosis of CHD among pediatric age groups can further swell the already occurring high mortality and morbidity rates. This is why, it is vital to identify and intervene early in cases with CHD to reduce morbidity and mortality among these cases. Data from developing countries have shown that early identification and appropriate treatment among CHD cases can reduce the mortality rates from 80 to $20 \% .^{9}$ Likewise, Patients requiring non-cardiac surgery, with suspected or symptomatic structural cardiac anomalies, may have increased peri-operative risk. Following to limited availability of echocardiographic services in the country, some patients being prepared for non-cardiac surgeries are referred for pre-anaesthetic cardiovascular evaluation, including echo. The cost of echo is often high and this increases the cost of surgery. This study was conducted to describe the spectrum including frequency and pattern of associated CHD in patients with non-cardiac congenital defects. Current study is representing our 1-year experience from one of the leading government pediatric tertiary care health facility of South Punjab, Pakistan.

\section{METHODS}

This was an observational study done at Paediatric Cardiology Department of The Children's Hospital and The Institute of Child Health, Multan, Pakistan, from December 2018 to November 2019. Approval from Institutional Ethical Committee was obtained for this study (Ref. No. 10, dated: 28-10-2018).

Children from birth to 15 years, referred by Pediatric Surgery Department of the same institution to Pediatric Cardiology Unit for cardiac evaluation during the study period were enrolled. Echocardiography was done in all the referred cases to rule out CHD. Critically ill patients who could not be shifted for echo and the patients with acquired cardiac disease were not enrolled. Likewise, patients having acquired surgical problems like trauma, infections, or tumors were not enrolled. Informed consent from parents/ guardians of all the enrolled participants was acquired. There was no conflict of interest as there was no financial aid involved.

A total of 323 children as per inclusion and exclusion criteria were enrolled during the study period. A special proforma was designed to record all the study data. Diagnosis of CHD was made on the basis of echocardiography findings, done by consultant pediatric cardiologist with a minimum post FCPS experience of five years. SPSS version 26.0 was used for data entry and analysis. Data was represented as frequencies and percentages.

\section{RESULTS}

Out of a total of 323 cases, majority, 176 (54.5\%) were male, $160(49.5 \%)$ aged one month to one year and $216(66.9 \%)$ had birth order as two or above as shown in Table-I.

Table-I: Overall Characteristics of Patients $(n=323)$.

\begin{tabular}{llc}
\hline \multicolumn{2}{l}{ Characteristics } & Number $(\%)$ \\
\hline \multirow{2}{*}{ Gender } & Male & $176(54.5 \%)$ \\
& Female & $147(45.5 \%)$ \\
& $<1$ month & $113(35.0 \%)$ \\
Age & $>$ 1 month to 1 Year & $160(49.5 \%)$ \\
& $>$ 1 to 5 years & $44(13.6 \%)$ \\
& $>$ 5 Years & $6(1.9 \%)$ \\
Birth & 1 & $107(33.1 \%)$ \\
Order & $>1$ & $216(66.9 \%)$ \\
\hline
\end{tabular}


Table-II: Distribution of Children with respect to Types of CHD and Primary Diagnosis ( $\mathrm{n}=323)$.

\begin{tabular}{|c|c|c|c|c|c|c|c|c|}
\hline Diagnosis & $\begin{array}{l}\text { Ompha- } \\
\text { locele }\end{array}$ & $\begin{array}{c}\text { ARM } \\
\text { Low } \\
\text { Variety }\end{array}$ & $\begin{array}{c}\text { ARM } \\
\text { High } \\
\text { variety }\end{array}$ & $\begin{array}{l}\text { Cleft Lip } \\
\mathcal{E} \text { Palate }\end{array}$ & $\begin{array}{l}\text { Cleft Lip } \\
\text { only }\end{array}$ & $\begin{array}{l}\text { Cleft Pal- } \\
\text { ate only }\end{array}$ & $\begin{array}{l}\text { Vascular } \\
\text { Malforma- } \\
\text { tions }\end{array}$ & Total \\
\hline Tetrology of Fallot & 1 & & 2 & & & & & 3 \\
\hline TGA with VSD with PS & & 1 & & & 1 & & & 2 \\
\hline TGA with VSD with $\mathrm{PH}$ & & & 1 & & & & & 1 \\
\hline VSD & & 1 & 1 & 4 & & & & 6 \\
\hline ASD & & 2 & & 1 & 1 & 1 & & 5 \\
\hline Complete AVSD & 1 & & & 1 & & & 3 & 5 \\
\hline PDA & & 3 & 3 & & 2 & 1 & 5 & 14 \\
\hline Tricuspid atresia & 1 & & & & & & & 1 \\
\hline Pulmonar Stenosis & & 1 & & & 1 & 1 & & 3 \\
\hline Coarctation of Aorta & & & & 1 & & & & 1 \\
\hline Cardiac TAPVC & & & & 1 & & & & 1 \\
\hline Total & 3 & 8 & 7 & 8 & 5 & 3 & 8 & 42 \\
\hline
\end{tabular}

Distribution of children with respect to types of CHD and primary diagnosis is shown in Table-II. Vascular malformations were the most seen in $69(21.4 \%)$ children followed by cleft lip and palate $55(17.2 \%)$, cleft palate only $52(16.1 \%)$, Cleft lip only $40(12.4 \%)$ and ARM high variety frequent primary diagnosis among our cases, $33(10.2 \%)$. CHD was found among $42(13.0 \%)$

Table-III: Distribution of CHD Cases $(\mathrm{n}=42)$.

\begin{tabular}{|c|c|c|c|c|c|c|c|}
\hline \multirow{2}{*}{ Type of CHD } & \multirow{2}{*}{ Number } & \multicolumn{2}{|c|}{ Gender } & \multicolumn{4}{|c|}{ Age Groups } \\
\hline & & Male & Female & $<1$ month & 1 month to 1 year & $>1-5$ years & $\begin{array}{c}>5 \\
\text { years }\end{array}$ \\
\hline Cyanotic & 8 & 5 & 3 & 3 & 4 & 1 & \\
\hline Tetralogy of Fallot & 3 & 2 & 1 & 1 & 1 & 1 & \\
\hline TGA with VSD with PS & 2 & 1 & 1 & 1 & 1 & & \\
\hline TGA with VSD with $\mathrm{PH}$ & 1 & 1 & & & 1 & & \\
\hline Tricuspid Atresia & 1 & & 1 & 1 & & & \\
\hline Cardiac TAPVC & 1 & 1 & & & 1 & & \\
\hline Acyanotic & 34 & 19 & 15 & 11 & 17 & 5 & 1 \\
\hline Ventricular septal defect & 6 & 3 & 3 & 2 & 3 & 1 & \\
\hline Atrial septal defect & 5 & 3 & 2 & 2 & 3 & & \\
\hline Patent ductus arteriosus & 14 & 8 & 6 & 3 & 7 & 3 & 1 \\
\hline Pulmonary valve stenosis & 3 & 1 & 2 & 1 & 2 & & \\
\hline Coarctation of aorta & 1 & 1 & & & 1 & & \\
\hline Complete AVSD & 5 & 3 & 2 & 3 & 1 & 1 & \\
\hline Total & 42 & 24 & 18 & 14 & 21 & 6 & 1 \\
\hline
\end{tabular}


children. Among these 42 children, patent ductus arteriosus and VSD were the commonest finding seen in $14(33.3 \%)$ and $6(14.3 \%)$ children respectively.

Table-III Distribution of CHD cases in terms of gender and age groups. Acyanotic CHD were observed among majority of the cases $(n=34$, $81.0 \%)$.

\section{DISCUSSION}

In the present study, frequency of associated $\mathrm{CHD}$ among patients with non-cardiac congenital defects was found to be $13.0 \%$. Data from Africa evaluating pre-anesthesia echo among patients of non-cardiac surgeries found that $21.5 \%$ of them had cardiac anomalies. ${ }^{2}$ Oyati AI et al recorded frequency of cardiac anomalies among patients undergoing non-cardiac surgeries as $35.0 \%$ which is quite high. ${ }^{8}$ Data from developing countries highlight that there are increased chances of a concurrent CHD among children having congenital anomalies. ${ }^{10}$ In Pakistan, incidence of CHD has not been calculated in the recent years but whatever data exists, it presented the incidence of CHD as 4/1000 live births ${ }^{11,12}$ while globally, it is estimated around 8/1000 live births. ${ }^{13,14}$ So, considering these statistics, our found frequency of CHD in the present study $(13.0 \%)$ is more than 32 times higher than what is usually found in the general population. So, these results from different parts of the world support our findings that we should perform echocardiography among cases undergoing surgery for non-cardiac congenital anomalies as there is an increased anaesthetic risk involved in such children.

In the present study, vascular malformations were the most frequent primary diagnosis, seen in $69(21.4 \%)$ children followed by cleft lip and palate $55(17.2 \%)$, cleft palate only $52(16.1 \%)$, cleft lip only $40(12.4 \%)$ and ARM high variety 33 $(10.2 \%)$. Not much work has been done analyzing presence of CHD among children having vascular malformations. We noticed that most number of children referred to us had vascular malformations. Blei $\mathrm{F}$ et al from United Stats evaluating cardiac screening of infants having hemangiomas observed that out of 239 children evaluated, $50(21 \%)$ of them had abnormal echocardiogram while out of those 50, 39 were having ASD while 6 had VSD. ${ }^{15}$ Among children having CHD ( $n=42)$, we noted PDA and VSD to be the commonest finding seen in $14(33.3 \%)$ and $6(14.3 \%)$ children respectively. In the present study, 38.1\% cases of diagnosed CHD had cleft lip and/or palate so these children should be given special attention during pre-surgery evaluation for the identification of any possible CHD. Echocardiography can be a worthy option among children who are having cleft lip and/or palate prior to any surgical corrections and it might be vital to correct the heart defect before going for the cleft lip and/or palate surgery. ${ }^{16}$

Oyati AI et al anlalyzing echocardiographic findings among children having non-cardiac congenital anomalies and undergoing surgeries noted that cleft lip or palate were the most frequent surgical anomalies seen in 38.3\% children followed by ano-rectal malformations seen in $26.7 \%{ }^{8}$ Sun $\mathrm{T}$ et al from Eastern China analyzing malformations linked with various kinds of orofacial clefts observed that out of 2180 children, $657(30.1 \%)$ were having some kind of congenital anomaly. However, CHD formed major chunk of those congenital anomalies accounting for 296/657 (45.1\%) cases. ${ }^{17}$ They also noted ASD to be the commonest CHD finding followed by VSD. Whereas, PDA was the $3^{\text {rd }}$ most frequent types of CHD. Acyanotic types of $\mathrm{CHD}$ formed the major chunk of CHD in the present study, accounting for $81.0 \%$ cases. These findings are consistent with the previous findings where acyanotic CHD has been observed to be the predominant portion of all cases of CHD among cases evaluated through echocardiography for non-cardiac surgery evaluation. ${ }^{18,19}$

Limitations of the study: It is a single center study of only one-year period. Larger, multi center studies over a longer period of time may reflect even better insight into the prevalence of CHD amongst patients with non-cardiac surgical problems. Furthermore, studies should also be planned to see the outcome of such cardiac patients after their non-cardiac surgical treatment.

\section{CONCLUSIONS}

Frequency of associated CHD among patients with non-cardiac congenital defects was high $(13.0 \%)$. Children with cleft lips and/or palate should be given more attention as they have got the highest incidence of CHD. Echocardiography must be advised for the timely identification of any possible type of $\mathrm{CHD}$ in all the patients presenting with non-cardiac congenital defects. 
Grant Support \& Financial Disclosure: None.

Conflict of Interest: None.

\section{REFERENCES}

1. Brown ML, DiNardo JA, Nasr VG. Anesthesia in pediatric patients with congenital heart Disease undergoing noncardiac surgery: Defining the risk. J Cardiothorac Vasc Anesth. 2020;34(2):470-478. doi: 10.1053/j.jvca.2019.06.015

2. Sadoh WE, Ikhurionam P, Imarengiaye C. Preanesthetic echocardiographic findings in children undergoing non-cardiac surgery at the University of Benin Teaching Hospital, Nigeria. Cardiovasc J Afr. 2016;27:1-5. doi: 10.5830/CVJA-2016-006

3. Zaidi S, Brueckner M. Genetics and Genomics of Congenital Heart Disease. Circ Res. 2017;120(6):923 940. doi: $10.1161 \%$ 2FCIRCRESAHA. 116.309140

4. Hewitt AL, Morrical BD, Cetta F. Cerebral arteriovenous malformation detected by newborn congenital heart disease screen with echocardiography. CASE (Phila). 2017;1(6):242-244. doi: 10.1016/j.case.2017.07.010

5. Otaigbe B, Akadiri O, Eigbobo J. Clinical and echocardiographic findings in an African pediatric population of cleft lip/palated patients: a preliminary report. Niger J Cardiol. 2013;10:6-8. doi: 10.4103/01897969.118574

6. Asani MO, Aliyu I. Pattern of congenital heart defects among children with orofacial clefts in Northern Nigeria. J Cleft Lip Palate Craniofacial Anom. 2014;1:85-87. doi: 10.4103/2348-2125.137895

7. Sun P, Ding G, Zhang M, He S, Gao Y, Wang J. Prevalence of congenital heart disease among infants from 2012 to 2014 in Langfang, China. Chin Med J (Engl). 2017;130(9):1069-1073. doi: 10.4103/03666999.204923

8. Oyati AI, Danbauchi SS, Ameh EA, Mshelbwala PM, Anumah MA, Ogunrinde GO, et al. Echocardiographic findings in children with surgically correctable noncardiac congenital anomalies. Ann Trop Paediatr. 2009;29(1):41-44. doi:10.1179/146532809X410359

9. Lopes SA, Guimarães IC, Costa SF, Acosta AX, Sandes KA, Mendes CMC. Mortality for Critical Congenital Heart Diseases and Associated Risk Factors in Newborns. A Cohort Study. Arq Bras Cardiol. 2018;111(5):666-673. doi:10.5935/abc.20180175
10. George IO, Frank-Briggs AI, Omamabo RS. Congenital rubella syndrome: Pattern and presentation in a southern Nigerian tertiary hospital. World J Pediatr. 2009;5:287291. doi: 10.1007/s12519-009-0054-x

11. Hassan I, Haleem AA, Bhutta ZA. Profile and risk factors for congenital heart disease. J Pak Med Assoc. 1997;47(3):78-81.

12. Patel N, Jawed S, Nigar N, Junaid F, Wadood AA, Abdullah F. Frequency and pattern of congenital heart defects in a tertiary care cardiac hospital of Karachi. Pak J Med Sci. 2016;32(1):79-84. doi: 10.12669/pjms.321.9029

13. Fyler DC, Buckley LP, Hellenbrand WE, Cohn HE. Report of the New England regional infant care program. Pediatrics. 1980;65(Suppl):375-461.

14. Abdullah R. What is the prevalence of Congenital Heart Disease? Ped Cardiol. 1997;18:268.

15. Blei F, McElhinney DB, Guarini A, Presti S. Cardiac screening in infants with infantile hemangiomas before propranolol treatment. Pediatr Dermatol. 2014;31(4):465470. doi: $10.1111 /$ pde. 12344

16. Junghare SW, Desurkar V. Congenital heart diseases and anaesthesia. Indian J Anaesth. 2017;61(9):744-752. doi: 10.4103/ija.IJA_415_17

17. Sun $\mathrm{T}$, Tian $\mathrm{H}$, Wang $\mathrm{C}$, Yin $\mathrm{P}$, Zhu $\mathrm{Y}$, Chen $\mathrm{X}$, et al. A Survey of Congenital Heart Disease and Other Organic Malformations Associated with Different Types of Orofacial Clefts in Eastern China. PLoS One 2013;8(1):e54726. doi: 10.1371/journal.pone.0054726

18. Otaigbe B, Akadiri O, Eigbobo J. Clinical and echocardiographic findings in an African pediatric population of cleft lip/palated patients: a preliminary report. Niger J Cardiol 2013;10:6-8. doi: 10.4103/01897969.118574

19. Asani MO, Aliyu I. Pattern of congenital heart defects among children with orofacial clefts in Northern Nigeria. J Cleft Lip Palate Craniofacial Anom. 2014;1:85-87. doi: $10.4103 / 2348-2125.137895$

\section{Authors Contribution:}

MSA: Conceived, responsible for data's authenticity and integrity.

MA: Data collection, literature review.

SA: Data collection, data interpretation, discussion.

MK: data analysis, drafting.
Authors:

1. Muhammad Sohail Arshad, FCPS (Pediatric Cardiology), Department of Pediatric Cardiology, The Children's Hospital \& The Institute of Child Health, Multan, Pakistan.

2. Muhammad Aslam, FCPS (Pediatric Surgery),

3. Shahnab Ahmad, FCPS (Pediatric Surgery),

4. Muhammad Kashif, FCPS (Pediatric Surgery),

2-4: Department of Pediatric Surgery,

The Children's Hospital \& The Institute of Child Health, Multan, Pakistan. 